\title{
Recurrent aphthous ulceration: an epidemiological study of etiological factors, treatment and differential diagnosis ${ }^{*}$
}

\author{
Salomão Israel Monteiro Lourenço Queiroz ${ }^{1}$ \\ Ana Miryam Costa de Medeiros ${ }^{1}$ \\ Bruno Cesar de Vasconcelos Gurgel ${ }^{1}$
}

\author{
Marcus Vinícius Amarante da Silva² \\ Patrícia Teixeira de Oliveira ${ }^{1}$ \\ Éricka Janine Dantas da Silveira ${ }^{1}$
}

DOI: http:/ / dx.doi.org/10.1590/abd1806-4841.20186228

\begin{abstract}
BACKGROUND: Recurrent aphthous ulcerations are common benign ulcerated lesions on the mouth, whose etiology is poorly understood, with controversial treatment and difficult to control in clinical practice.

Овјестіvе: To evaluate the cases of recurrent aphthous ulcerations with a focus on treatment, diagnosis and etiology.

Methods: This is a retrospective study of the cases of the Oral Diagnosis service of the Rio Grande do Norte Federal University in Natal/RN. Data such as sex, age, race, location, smoking habits, types of treatment, relapsing episodes, laboratory test results and clinical characteristics were collected. The associations between the variables were analyzed using the Pearson Chi-square test $(\mathrm{p}<0.05)$.

RESULTS: A total of 4895 patients were seen in the service over a period of 11 years. Of these, 161 (3.3\%) had complaints of oral aphthous ulcerations, of which $76(47.2 \%)$ were diagnosed as suffering from recurrent aphthous ulcerations and 68 (42.2\%) with clinical information necessary for evaluation. The tongue was the most affected anatomical region, with 27 individuals $(39.7 \%)$, followed by the buccal mucosa, with 22 cases $(32.3 \%)$.

STUDY LIMITATIONS: Retrospective study with data from medical records.

CONCLUSION: Dental surgeons, dermatologists and otorhinolaryngologists are the main responsible for the first contact with patients with this disease and should be attentive to the clinical aspects and treat each patient in an individualized way, since the therapy is palliative, its diagnosis is by exclusion and its etiology is unknown.
\end{abstract}

Keywords: Diagnosis; Mouth mucosa; Stomatitis, aphthous; Therapeutics

\section{INTRODUCTION}

The term aphthous comes from the Greek word "aphtha", meaning ulcer. Aphthous ulcers or recurrent aphthous stomatitis (RAS) are benign ulcerated lesions common on the mouth, with uncertain etiology, still controversial treatment and a differential diagnosis that requires attention and clinical experience. ${ }^{1,2}$

Clinically, RAS is divided into three forms: minor, major and herpetiform. The most common clinical presentation, the minor form, is responsible for $70 \%$ to $85 \%$ of all RAS, characterized by circular, ovoid or elongated lesions with a crateriform base, measuring less than $1 \mathrm{~cm}$ in diameter, covered by a white-gray pseudomembrane and with a resolution time of 10 to 14 days. ${ }^{1,3}$ The number of ulcerations is also important and the minor RAS usually vary from one to five and usually do not cause scarring. ${ }^{1-4}$

The major form is less common than the minor, representing around $7 \%$ to $20 \%$ of the cases, have more than $1 \mathrm{~cm}$ in diameter, are deeper and can be associated to dysphagia and can last for months, leaving scars. The dysphagia is associated to the site of the lesion, being more frequent in the internal mucous membrane of the lip, tongue and soft palate. ${ }^{2,3}$

The herpetiform form is rare and presents as groups of pinpoint ulcers in $5 \%$ to $10 \%$ of RAS, with a size of $0.1-0.2 \mathrm{~cm}$ and in large number (5-100 ulcers at the same time). They can coalesce

\footnotetext{
Received 15 July 2016.

Accepted 03 April 2017.

* Work conducted at Universidade Federal do Rio Grande do Norte (UFRN), Natal (RN), Brazil.

Financial support: None.

Conflict of interest: None.

Oral Pathology Post-Graduation Program, Universidade Federal do Rio Grande do Norte (UFRN), Natal (RN), Brazil.

Odontology Department (Graduation), Universidade Federal do Rio Grande do Norte (UFRN), Natal (RN), Brazil.
}

MAILING ADDRESS:

Éricka Janine Dantas da Silveira and Salomão Israel Monteiro Lourenço Queiroz

E-mail: ericka_janine@yahoo.com.br and salomaoisrael10@gmail.com

(C)2018 by Anais Brasileiros de Dermatologia 
forming a large and irregular lesion that can have a clinical course of 7-14 days. Despite the name and its features, the herpes simplex virus (HSV) is not identified in these lesions. ${ }^{4,5}$

RAS do not have a clear etiology and, in some cases, are of difficult control and treatment, causing discomfort to the patients. The development of recurrence can be related to hereditary, psychosomatic, infectious, hormonal (periods, pregnancy or post-menopausal) factors, trauma, stress, food allergies, nutritional deficiencies (iron, vitamin B12 and folic acid) and hematological abnormalities. However, the absence of biochemical and histological specific changes characterizes this condition and allow to make the diagnosis of recurrent aphthous ulcers. ${ }^{6,7}$

Its similarities with other mucocutaneous, oral ulceration conditions make the diagnosis difficult, in a way that the differential diagnosis with other lesions such as herpes, chickenpox, erythema multiforme, erosive lichen planus with ulceration, Sutton's ulcers, Riga-Fede disease, pemphigus vulgaris and pemphigoid should be based in the clinical features, location and course of the ulcerations. ${ }^{2,4,6}$

There are many attempts to find the ideal treatment for this condition, however, some patients do not need treatment due to the mild nature of the disease whereas others, who experience multiple episodes for months and/or with severe symptoms of pain and difficulty eating, should be treated in a palliative way., ${ }^{2,8}$ Topical agents are the first treatment of choice because they are safe and effective, with few side effects and have a lower chance of drug interaction. ${ }^{3,9}$

In view of the controversies that are still inherent to RAS mainly regarding its etiology, treatment and diagnosis, the objective of this study was to analyze sociodemographic characteristics, diagnostic maneuvers and treatment in a series of RAS cases diagnosed in a Oral Diagnosis service of the Universidade Federal do Rio Grande do Norte in Natal/RN.

\section{METHODS}

This study consisted of a retrospective analysis of all cases with the clinical diagnosis of RAS in patients at the service of oral diagnosis of the Universidade Federal do Rio Grande do Norte in Natal/RN, for 11 years (2003-2014). This research was approved by the ethical comittee in research of the Universidade Federal do Rio Grande do Norte under the number 148.865 .

In the clinical records, information like sex, age, race, site, smoking habits, types of treatment, recurrence episodes, laboratory exams results from full blood count, fasting glucose, serum alkaline phosphatase, serum calcium, serum phosphate, serum vitamin B12 were collected. And, specific antibodies for cases of autoimmune diseases with a clinical similar presentation, like as pemphigoid and pemphigus vulgaris were investigated. Biopsy was performed in cases of lack of improvement of the lesion. And, clinical features of the lesions for the classification of RAS subtype were also recorded . All images were obtained according to the authorization term of the Universidade Federal do Rio Grande do Norte in Natal/RN (stomatology evaluation form), signed by the patients at the first consultation.

The files with the above-mentioned information were included in the study. The files from patients with the clinical diagno- sis of RAS but who after the clinical and laboratory analysis did not have RAS, meaning lesions resulting from traumas, broken teeth, syndromes and ill adapted prosthesis, with no relapsing episodes were excluded.

The data collected were processed and transcribed to the Statistical Package for the Social Sciences, version 17 (SPSS Inc.; Chicago, USA, 2008). The descriptive analyses were performed based on the mean and standard deviation for quantitative variables and absolute and relative frequencies for categorical variables. The association between categorical variables was analyzed using Pearson's chi-square test with prevalence ratio and confidence interval of $95.0 \%$ for variables with significant associations. The level of significance adopted was of $5.0 \%$.

\section{RESULTS}

In the period studied, 4895 patients were seen at the Oral Diagnosis service and of these, $161(3.3 \%)$ had a clinical diagnosis of oral aphthous ulcers and $76(47.2 \%)$ were diagnosed with RAS. The other $85(52.8 \%)$ cases were excluded based on the proposed methodology, fundamental for the correct diagnosis of the condition, and eight $(4.9 \%)$ because they did not have the necessary clinical information to conduct the research.

Of the 68 RAS cases with suitable recorded data, 40 (59.2\%) were female and $28(40.8 \%)$ were male, with a mean age of $41.9( \pm$ 16.5) years. The mixed-race individuals were the most frequent $30(44.1 \%)$ followed by Caucasian with 23 (33.8\%) and black with nine $(13.2 \%)$, being this information unavailable in six cases $(8.8 \%)$. Regarding smoking habits, in the majority of patients, 59 (77.6\%) this information was not recorded, being the frequency of smokers in the reported cases of four $(44.4 \%)$ and former smokers of five (55.6\%), all 40 years of age or older. It is important to highlight that the percentages of smoking notifications will not be considered because they are influenced by a bias of selection of the sample.

The tongue was the most commonly affected anatomical region, with 27 patients (representing $27 \%$ of the sites and $39.7 \%$ of the patients) followed by the buccal mucosa with 22 (representing $22 \%$ of the sites and $32.3 \%$ of the patients), remarking that 21 patients had lesions in more than one anatomical site (from 2 to 4 ), with a total of 100 sites and 68 patients (Table 1). One case was diagnosed as herpetiform $(1.5 \%)$, three as major RAS $(4.4 \%)$ and the remaining as minor (Figure 1).

The main reported symptoms by patients was pain (50\%) followed by burning pain (25\%) and other symptoms such as dysphagia, dysgeusia, and stinging pain (13.2\%). And, in $11.7 \%$ of the cases no symptoms were reported. In the majority of cases $(70.3 \%)$ the etiology was not identified, but possible factors such as physical or chemical trauma $(13.5 \%)$, stress $(8.8 \%)$ and nutritional and immunological deficiencies (7.3\%) were reported but, later ruled out, supporting the confirmation of the diagnosis of RAS, thorough clinical investigation and use of ancillary tests.

The most used treatment was topical corticosteroids such as dexamethasone, betamethasone and clobetasol propionate $0.05 \%$ (26.5\%), all as an elixir, followed by triamcinolone acetonide $0.05 \%$ (Omcilon-A orabase $^{\circledR}$ ) $(14.7 \%)$. In $38.2 \%$ of patients there was no treatment, only follow-up for two weeks. Other forms of treatment 
such as tetracycline mouth washes $(8.8 \%)$, nonsteroidal anti-inflammatories $(5.9 \%)$ and oral solution of nystatin when associated to candidiasis, besides vitamin C and low intensity laser (5.9\%) were also used.

\begin{tabular}{|c|c|c|c|c|}
\hline \multirow[t]{2}{*}{ Site } & \multicolumn{2}{|c|}{$\begin{array}{c}\text { Percentage based } \\
\text { on the } 100 \text { sites } \\
\text { evaluated }\end{array}$} & \multicolumn{2}{|c|}{$\begin{array}{c}\text { Percentage } \\
\text { based on } 68 \\
\text { patients }\end{array}$} \\
\hline & $\mathbf{n}$ & $\%$ & $\mathbf{n}$ & $\%$ \\
\hline Tongue & 27 & 27.0 & 27 & 39,7 \\
\hline Buccal mucosa & 22 & 22.0 & 22 & 32,3 \\
\hline Upper and lower lip & 20 & 20.0 & 20 & 29,4 \\
\hline Oral vestibule & 14 & 14.0 & 14 & 20,6 \\
\hline Floor of the mouth & 10 & 10.0 & 10 & 14,7 \\
\hline Soft palate & 7 & 7.0 & 7 & 10,3 \\
\hline Total & 100 & 100.0 & 68 & * \\
\hline
\end{tabular}

* The total percentage of the patients exceeds $100 \%$, because the same patient could have had lesions on more than one site.
Separately evaluating each site of the lesions, we observed a significant association of patients younger than 40 years of age with RAS on the buccal mucosa ( $p=0.025$; prevalence ratio $=2.140$ and $95 \%$ confidence interval $=1.301-3.256$ ), meaning that patients younger than 40 years of age had more than $100 \%$ chances of being associated to the occurrence of lesions on the buccal mucosa (Table 2).

When sex and site of the lesions were evaluated, we observed a significant association $(\mathrm{p}=0.009$; prevalence ratio $=2.541$ and $95 \%$ confidence interval $=1.320-3.782$ ) between the fact of being male and having lesions on the buccal mucosa, meaning that men have more than $150 \%$ chances of being associated with lesions on the buccal mucosa (Table 3).

Regarding the clinical follow-up of the patients, the majority $(88 \%)$ reported improvement with the treatment prescribed at the time of the diagnosis of the condition, even with relapsing episodes. Figures 2 and 3 belong to a RAS case treated with clobetasol propionate $0.05 \%$ (rinses of $10 \mathrm{ml}$ for one minute, three times a day for 15 days).

\section{DISCUSSION}

RAS is a common condition of the oral mucosa that affects mainly non-keratinized tissues. It usually starts during childhood,
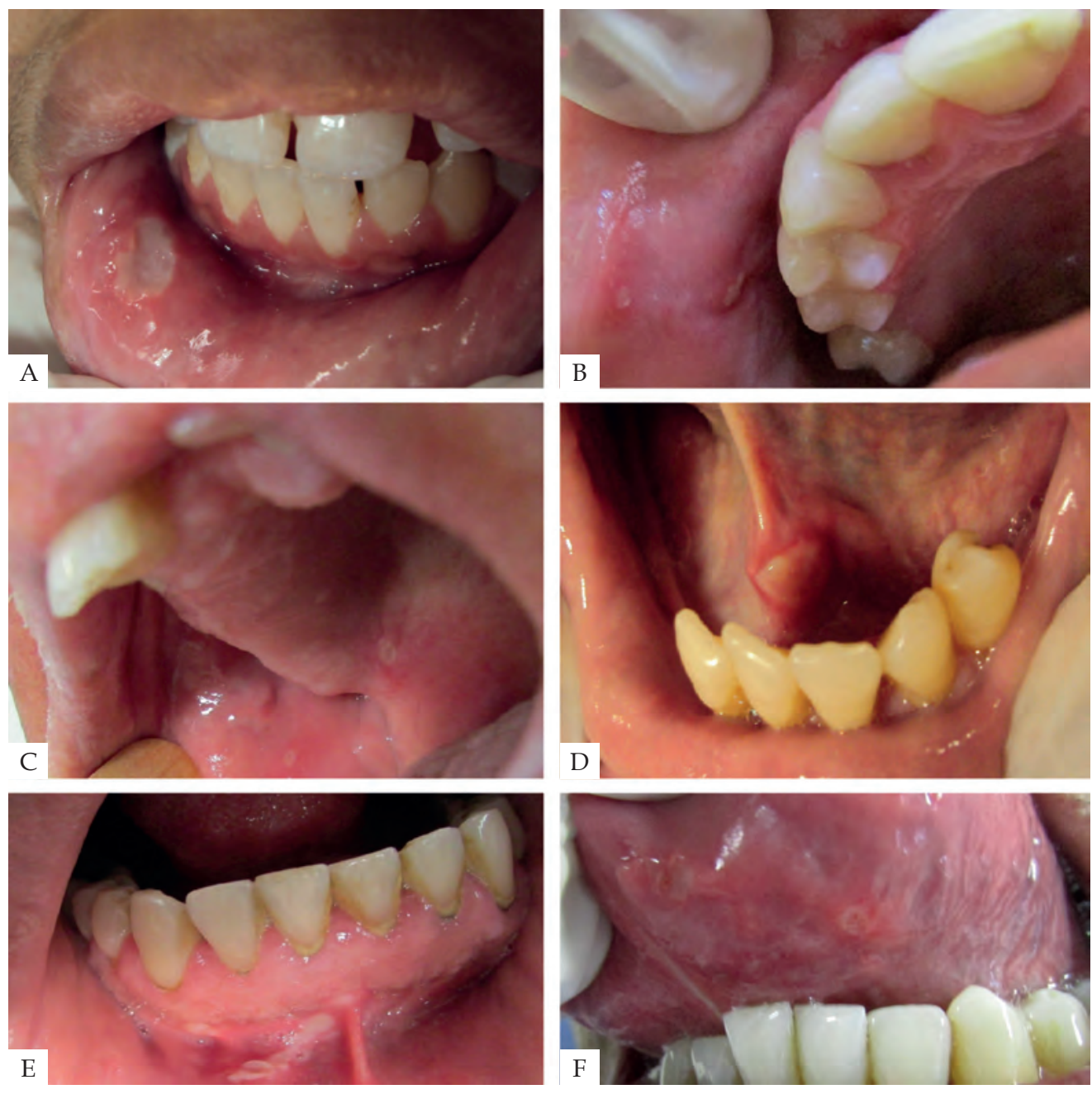

Figure 1: Anatomical sites of RAS. a: Lower lip (Major RAS), b: Upper lip (Minor RAS), c: Buccal mucosa and soft palate (Herpetiform RAS), d: Floor (Major RAS), and: Oral vestibule (Major RAS) and f: Tongue (Minor RAS) 
is recurrent, symptomatic and has the clinical presentation as ulcers, which can be single or multiple. It has been reported that its prevalence ranges from $5 \%$ to $60 \%$ of the population. ${ }^{1,10}$ In this present research, its prevalence was of $1.4 \%$ during a period of 11 years, which is lower than what is reported in the literature. This fact may suggest that many people affected by this condition do not seek odontological care for the diagnosis and treatment, since they have a short and self-limited clinical course. Prevalence studies of this condition are important because they expose the profile of the population affected, etiological factors and the experience regarding to diagnosis and treatment. Unfortunately, we face difficulties to conduct this type of study because it is a retrospective study with data based on patient's records, limiting the evaluation and clinical course to what is reported in the file, which are many times neglected such as in the

TABLE 2: Anatomical sites of recurrent aphthous ulcers according to the age group

\begin{tabular}{|c|c|c|c|c|c|c|}
\hline \multirow[t]{3}{*}{ Site } & & \multicolumn{4}{|c|}{ Age in age group } & \multirow[b]{3}{*}{ p } \\
\hline & & \multicolumn{2}{|c|}{$<40$} & \multicolumn{2}{|c|}{40 or older } & \\
\hline & & $\mathbf{n}$ & $\%$ & $\mathbf{n}$ & $\%$ & \\
\hline \multirow[t]{2}{*}{ Buccal mucosa } & Yes & 14 & 46.6 & 8 & 21.1 & 0.025 \\
\hline & No & 16 & 53.4 & 30 & 78.9 & \\
\hline \multirow[t]{2}{*}{ Tongue } & Yes & 13 & 43.3 & 14 & 36.8 & 0.587 \\
\hline & No & 17 & 56.7 & 24 & 63.2 & \\
\hline \multirow[t]{2}{*}{ Lip } & Yes & 9 & 30.0 & 11 & 28.9 & 0.925 \\
\hline & No & 21 & 70.0 & 27 & 71.1 & \\
\hline \multirow[t]{2}{*}{ Oral vestibule } & Yes & 6 & 20.0 & 6 & 15.8 & 0.651 \\
\hline & No & 24 & 80.0 & 32 & 84.2 & \\
\hline \multirow[t]{2}{*}{ Soft palate } & Yes & 1 & 3.3 & 7 & 18.4 & 0.076 \\
\hline & No & 29 & 96.7 & 31 & 81.6 & \\
\hline \multirow[t]{2}{*}{ Floor } & Yes & 4 & 13.3 & 6 & 15.8 & 1.000 \\
\hline & No & 26 & 86.7 & 32 & 84.2 & \\
\hline
\end{tabular}

TABLE 3: Anatomical sites of recurrent aphthous ulcerations according to sex

\begin{tabular}{|c|c|c|c|c|c|c|}
\hline \multirow[t]{3}{*}{ Site } & & \multicolumn{4}{|c|}{ Sex } & \multirow[b]{3}{*}{$p$} \\
\hline & & \multicolumn{2}{|c|}{ Male } & \multicolumn{2}{|c|}{ Female } & \\
\hline & & $\mathbf{n}$ & $\%$ & $\mathbf{n}$ & $\%$ & \\
\hline \multirow[t]{2}{*}{ Buccal mucosa } & Yes & 14 & 50.0 & 8 & 20.0 & 0.009 \\
\hline & No & 14 & 50.0 & 32 & 80.0 & \\
\hline \multirow[t]{2}{*}{ Tongue } & Yes & 11 & 39.3 & 16 & 40.0 & 0.953 \\
\hline & No & 17 & 60.7 & 24 & 60.0 & \\
\hline \multirow[t]{2}{*}{ Lip } & Yes & 11 & 39.3 & 9 & 22.5 & 0.135 \\
\hline & No & 17 & 60.7 & 31 & 77.5 & \\
\hline \multirow[t]{2}{*}{ Oral vestibule } & Yes & 4 & 14.3 & 8 & 20.0 & 0.543 \\
\hline & No & 24 & 85.7 & 32 & 80.0 & \\
\hline \multirow[t]{2}{*}{ Soft palate } & Yes & 2 & 7.1 & 6 & 15.0 & 0.322 \\
\hline & No & 26 & 92.9 & 34 & 85.0 & \\
\hline \multirow[t]{2}{*}{ Floor } & Yes & 4 & 14.3 & 6 & 15.0 & 0.935 \\
\hline & No & 24 & 85.7 & 34 & 85.0 & \\
\hline
\end{tabular}

case of smoking habits in our sample (77.6\% was not reported). The lack of notification of smoking habit should be considered an alert for this information to be collected with more interest in the future because it is an important risk factor for the development of many oral conditions.

The etiology of RAS is still poorly understood but Sawair ${ }^{10}$, in 2010, mentions that factors such as stress, physical and/or chemical trauma, food sensitivity and genetic predisposition can favor recurrent episodes of the condition. ${ }^{2,9,10}$ Mahmoud et al. ${ }^{11}$, in 2012, characterized this disease as presenting a multifactorial etiology. Regarding genetic predisposition, it has been reported that around $40 \%$ of RAS patients have a family history and are likely to develop the condition earlier and more severely.,4,9

Mahmoud et al. ${ }^{11}$ research investigated the psychological profile of 50 RAS patients, and detected that either stress situations or anxiety can favor the recurrence episodes of this condition. The authors explain that in stressful situations the concentration of salivary cortisol increases and there is a subsequent stimulus of the immunological system for the recruitment of leukocytes to inflammation sites, having an essential role in the pathogenesis of the con-

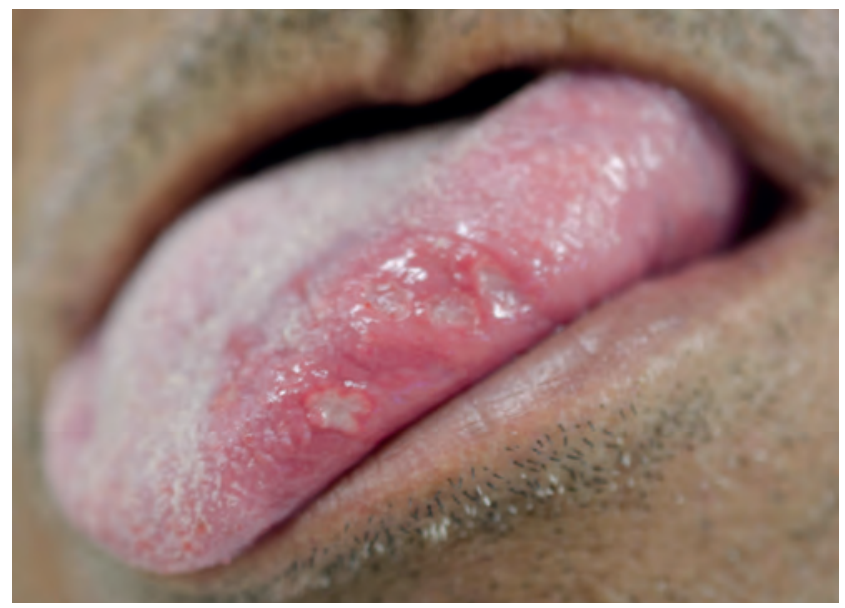

FIGURE 2: Major RAS on the left lateral border of the tongue

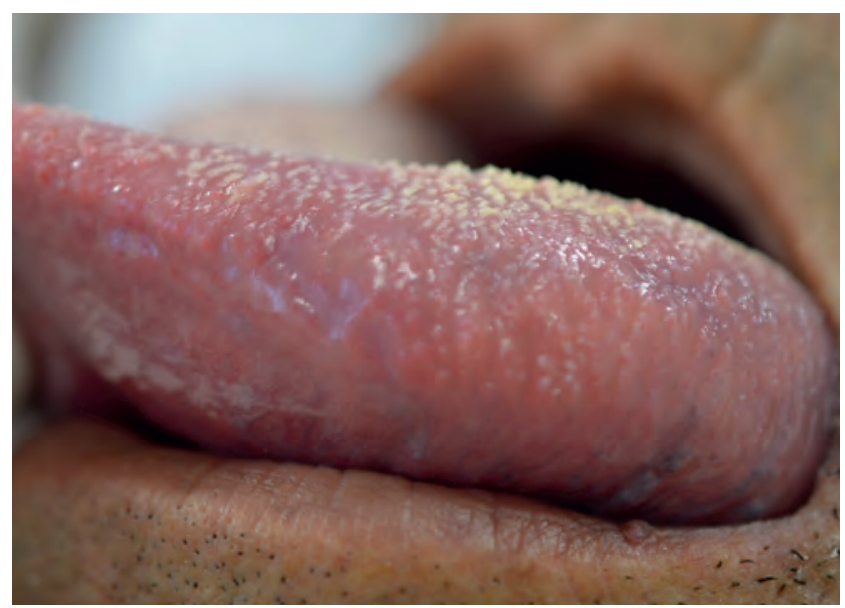

Figure 3: Clinical follow-up after 15 days, evidencing successful treatment and remission of the lesion and pain symptoms 
dition. ${ }^{10,11}$ In this study, because it was a retrospective analysis, it was not possible to identify any associated psychological factor.

Sawair ${ }^{10}$ found that smoking had a protective effect on the mucosa of smokers for recurrence episodes of aphthous ulcers. In our study, it was not possible to verify this association since this information was not available.

Nutritional deficiencies have also been associated to the predisposition of recurrence episodes of RAS. Singh ${ }^{12}$ reported that deficiencies in vitamins B1, B2, B6, B12 and iron can be associated to these episodes. Based on this, they investigated the serum concentration of vitamin B12 and folic acid in 160 patients and divided them into two groups, one that received daily supplements of vitamins and another that did not and, observed that this maneuver did not cause a reduction in the episodes of recurrence of RAS.

Some studies report that RAS is a lesion with high prevalence in women. ${ }^{7,13}$ However, despite showing the high prevalence among women, the results of this study do not confirm the hypothesis of the existence of a relationship between this condition and gender, confirming other reports such as Lima et al. ${ }^{13}$ and Chattopadhyay and Shetty ${ }^{14}$, who also demonstrated the lack of association between RAS and gender. This high prevalence in women can be explained by the fact that women seek more medical attention. In this study, we observed an association between being male and lesions on the buccal mucosa, what could explain why men seek less the attention of our service, since this site causes less discomfort to the patient.

Depending on the site of the RAS and the age of the patients, some authors affirm that RAS can be more or less painful. Usually, lesions on areas of friction while eating such as the soft palate, tongue and, among elderly patients, because of the reduced ability for tissue repair, would be more associated to larger and more painful RAS., In this study, age younger than 40 years was more associated to having a lesion on the buccal mucosa, location where these lesions would possibly be smaller and less painful, what could explain the fact that lesions in younger patients are less painful and smaller. It is also worth highlighting that patients with advanced age have fewer teeth than younger patients, predisposing to trauma of the oral mucosa during mastication.

To establish the diagnosis of RAS, clinical history reported by the patients and thorough examination of the mouth are indispensable. ${ }^{6,7}$ Family history, frequency of appearance, duration, number, site (keratinized or non-keratinized tissue), size and shape of the ulcers are also important for the guidance of diagnosis. ${ }^{2,3}$ It is important to say that there is no specific laboratory test for the diagnosis of RAS and that the histopathological findings are nonspecific but, complementary tests such as full blood count, dosage of inflammatory and hematological markers and vitamins, as well as serologies are useful tools to rule out possible systemic conditions that can cause oral ulcerations. ${ }^{3,15}$

Primary herpetic stomatitis can be mistaken with RAS, as well as the recurrent in its intraoral form but, the primary form of herpetic stomatitis has systemic involvement such as fever. The vesicle phase can be seen on the oral mucosa and, when as an ulcer, it is more erythematous and diffuse on different sites, particularly on keratinized mucosa, what is uncommon in RAS. ${ }^{2,8}$
Approximately two thirds of oral lichen planus cases present as an ulcer, but its occurrence in keratinized mucosa is more common that RAS, however, the diagnosis of lichen planus can be confirmed by histological examination and it is possible to identify discrete white streaks interspersed with the ulcerations in the erosive form. Vesiculobullous lesions such as in pemphigoid and pemphigus vulgaris, result in painful ulcerations that can be mistaken with RAS, being the follow-up and subsequent biopsy, after the lack of improvement, fundamental for the confirmation of the diagnosis. ${ }^{3,14}$

Riga-Fede disease is characterized by a reactive ulceration of the oral mucosa associated to repetitive dental trauma. It was initially described in children with neurologic deficit, being very rare in adults. Its similarity to other ulcerations can make its differential diagnosis difficult. One important feature of this condition is that complete resolution usually occurs after neurological recovery. ${ }^{4}$

RAS can also develop secondarily to systemic conditions such as acquired immunodeficiency syndrome (AIDS), celiac disease, Crohn's disease, Behçet's and Router syndrome, and in these cases the treatment should be multidisciplinary. ${ }^{16,17}$ In this study, there were no reports of the association of RAS with any of those systemic conditions. Regarding the treatments used, Chattopadhyay and Shetty ${ }^{14}$, in 2011, mentioned topical or intralesional corticosteroids and local anesthetics as the most commonly used for palliative treatment, with the aim to provide symptomatic relief in controlling the pain and reducing the number of future ulcers without curing, since there is no specific treatment for RAS aiming at the cure of the lesions.

Pensin et al.$^{18}$ conducted a research with 30 participants with a history of RAS, with a minimal frequency of 4 episodes per year where they were treated with a propolis ointment, a resinous compound produced by bees for protection of the hive, as a $5 \%$ orabase ointment. The research demonstrated that the use of this ointment reduced the pain and the time for healing and promoted a longer disease-free interval in RAS patients.

Meng et al. ${ }^{19}$ conducted a study where they investigated and compared efficacy results of amlexanox (anti-allergic and anti-inflammatory agent) per os, in the form of adhesive sheets and amlexanox tablets for the treatment of recurrent minor aphthous ulcers, in order to analyze the differences between both forms. The authors concluded that there was no significant difference in the efficacy between the two types of treatment. In our study the treatment most used was topical corticosteroids.

Laser has also been used for the treatment of RAS. Low potency laser and $\mathrm{CO}_{2}$ laser have been tested in the reduction of healing time of these lesions. ${ }^{20,21}$ Zand et al. ${ }^{21}$ concluded, after performing a randomized, blind controlled clinical trial, that $\mathrm{CO}_{2}$ laser can be used to speed minor RAS healing with no visible side effects even though its analgesic effects are more important than its curative effects. The authors highlight the fact that their study is still a pilot study, with subsequent studies needed with larger samples.

Besides topical treatments, there are systemic treatments such as thalidomide, prednisone and dapsone. According to Mimura et al. ${ }^{22}$, those medications have anti-inflammatory and immunosuppressant properties that can reduce or avoid the development of 
RAS. From this, they performed a study treating patients with Sutton's ulcers, the major clinical form of RAS, with these medications and concluded that thalidomide was the most effective drug, with very good responses in the majority of cases, in a way that in seven patients there was complete resolution of the lesions.

Volkov et al. ${ }^{23}$ found low levels of serum levels of vitamin B12 in three young and healthy patients with recurrent aphthous ulcers. Vitamin B12 was replaced according to the protocol and lead to a rapid improvement and complete recovery within a few weeks. In 6 months, follow-up of all three patients did not show recurrence of the lesions. In our study, no patient was treated systemically with vitamin B12, only topically with a gel or elixir on corticosteroid base, however, it is possible that the association of the local with the systemic treatment, particularly the vitamin-based, can contribute to the reduction of the recurrence episodes of these lesions.

It is important to highlight that the patient must be informed that the treatment is palliative and that they must observe the factors more related to the recurrence episodes. It has been reported that in some cases the patients are resistant to treatment and the above-mentioned therapeutics is used only as palliative for the control and relief of pain. ${ }^{2,3}$

\section{CONCLUSIONS}

The treatment and, many times, the diagnosis of RAS are a challenge in the daily life of the clinician. Dental surgeons, dermatologists, otorhinolaryngologists and physicians are usually responsible for the first contact with the patients who have this disease. These professionals should be alert to the clinical aspects of this condition since each patient will be treated in an individualized manner, because treatment is usually palliative and not curative. Even without a proven etiology, the identification of the factors associated to the recurrence episodes is important to check possible risks of aggravation of the pain symptoms for each patient. The differential diagnosis of RAS with other oral ulcerations is already well-established, being paramount a clinical experience for a thorough clinical examination, since its diagnosis is many times follows the exclusion of other conditions. $]$

\section{REFERENCES}

1. Alves PM, Ramalho LS, Oliveira RS, Cavalcanti AL, Queiroz LMG. Fatores de risco da ulceração aftosa recorrente: uma revisão dos achados atuais. Rev. Ciênc. Méd. Biol. 2008;7:76-84

2. Hamedi S, Sadeghpour 0, Shamsardekani MR, Amin G, Hajighasemali D, Feyzabad Z. The Most Common Herbs to Cure the Most Common Oral Disease: Stomatitis Recurrent Aphthous UIcer (RAU). Iran Red Crescent Med J. 2016;18:e21694.

3. Tarakji B, Gazal G, Al-Maweri SA, Azzeghaiby SN, Alaizari N. Guideline for the Diagnosis and Treatment of Recurrent Aphthous Stomatitis for Dental Practitioners. J Int Oral Health. 2015;7:74-80.

4. Calistru AM, Lisboa C, Bettencourt H, Azevedo F. Case for diagnosis. Riga-Fede disease. An Bras Dermatol. 2012:87:791-2.

5. Curvelo JAR, Ferreira DC, Carvalho FCR, Janini MER. Úlceras aftosas recorrentes e sua possível associação ao estresse. Rev. Ciênc. Méd. Biol. 2008;7:67-75.

6. Preeti L, Magesh K, Rajkumar K, Karthik R. Recurrent aphthous stomatitis. J Oral Maxillofac Pathol. 2011;15:252-6.

7. Safadi RA. Prevalence of recurrent aphthous ulceration in Jordanian dental Patients. BMC Oral Health. 2009;9:31

8. Natah SS, Konttinen YT, Enattah NS, Ashammakhi N, Sharkey KA, HäyrinenImmonen R.. Recurrent aphthous ulcers today: a review of the growing knowledge. Int J Oral Maxillofac Surg. 2004;33:221-34.

9. Scully C, Porter S. Oral mucosal diseases: recurrent aphthous stomatitis. Br J Oral Maxillofac Surg. 2008;46:198-206.

10. Sawair FA. Does smoking really protect from recurrent aphthous stomatitis? Ther Clin Risk Manag. 2010;6:573-7.

11. Al-Omiri MK, Karasneh J, Lynch E. Psychological profiles in patients with recurrent aphthous ulcers. Int J Oral Maxillofac Surg. 2012;41:384-8.

12. Singh M. Daily Supplementation of recommended dose of multivitamin does not reduce the frequency and duration of recurrent aphthous ulcers. J Evid Based Dent Pract. 2013;13:27-8.
13. Leonardo LM, Diogo DM, Jr Arnaldo CF, Fabíola AB, Verônica RMS, Jr Luiz Gutenberg CTM et al. Prevalence and risk factors for the development of recurrent aphthous stomatitis. Rev Cir Traumatol Buco-Maxilo-Fac. 2010;10:61-6.

14. Chattopadhyay A, Shetty KV. Recurrent Aphthous Stomatitis. Otolaryngol Clin North Am. 2011;44:79-88.

15. Baccaglini L, Theriaque DW, Shuster JJ, Serrano G, Lalla RV. Validation of anamnestic diagnostic criteria for recurrent aphthous stomatitis. J Oral Pathol Med. 2013;42:290-4.

16. Costacurta M, Maturo P, Bartolino M, Docimo R. Oral Manifestations of Coeliac Disease. A Clinical-statistic Study. Oral Implantol (Rome). 2010;3:12-9.

17. Coelho K, Araújo CSA. Tratamento de ulcerações aftosas recorrentes: uma revisão bibliográfica. Publ. UEPG Ci Biol Saúde. 2006;11:39-45.

18. Pensin NR, Pensin C, Miura CSN, Boleta-Ceranto DC. Efeito de pomada de própolis em orabase para tratamento de ulcerações aftosas recorrentes: um estudo piloto. Arq Ciênc Saúde UNIPAR. 2009; 13:199-204.

19. Meng W, Dong Y, Liu J, Wang Z, Zhong X, Chen R, et al. A clinical evaluation of amlexanox oral adhesive pellicles in the treatment of recurrent aphthous stomatitis and comparison with amlexanox oral tablets: a randomized, placebo controlled, blinded, multicenter clinical trial. Trials. 2009;10:30.

20. Anand V, Gulati M, Govila V, Anand B. Low level laser therapy in the treatment of aphthous ulcer. Indian J Dent Res. 2013;24:267-70.

21. Zand N, Fateh M, Ataie-Fashtami L, Djavid GE, Fatemi SM, Shirkavand A Promoting Wound Healing in Minor Recurrent Aphthous Stomatitis By NonThermal, Non-Ablative C02 Laser Therapy: A Pilot Study. Photomed Laser Surg. 2012;30:719-23.

22. Mimura MA, Hirota SK, Sugaya NN, Sanches Jr JA, Migliari DA. Systemic treatment in severe cases of recurrent aphthous stomatitis: an open trial. Clinics (Sao Paulo). 2009;64:193-8.

23. Volkov I, Rudoy I, Abu-Rabia U, Masalha T, Masalha R. Case Report: recurrent aphthous stomatitis responds to vitamin B12 treatment. Can Fam Physician. 2005 Jun; $51: 844-5$.

$\begin{array}{ll}\text { Patrícia Teixeira de Oliveira } & \text { (ID) ORCID 0000-0002-0641-1033 } \\ \text { Bruno Cesar de Vasconcelos Gurgel } & \text { (iD) ORCID 0000-0001-5971-134X } \\ \text { Éricka Janine Dantas da Silveira } & \text { (iD) ORCID 0000-0003-2128-0147 }\end{array}$

Éricka Janine Dantas da Silveira $\quad$ iD ORCID 0000-0003-2128-0147

$\begin{array}{ll}\text { Salomão Israel Monteiro Lourenço } & \text { (iD) ORCID 0000-0003-0150-9522 } \\ \text { Queiroz } & \text { (D) ORCID 0000-0002-4689-6223 } \\ \text { Marcus Vinícius Amarante da Silva } & \text { (iD) ORCID 0000-0003-1839-1030 } \\ \text { Ana Miryam Costa de Medeiros } & \end{array}$

How to cite this article: Queiroz SIML, Silva MVA, Medeiros AMC, Oliveira PT, Gurgel BCV, Silveira EJD. Recurrent aphthous ulceration: an epidemiological study of etiological factors, treatment and differential diagnosis. An Bras Dermatol. 2018;93(3):341-6. 